TITLE:

\title{
Thermal Properties of Ionic Liquid + Water Binary Systems Applied to Heat Pipes
}

$\operatorname{AUTHOR}(S):$

Nakata, Yoshito; Kohara, Kimio; Matsumoto, Kazuhiko; Hagiwara, Rika

\section{CITATION:}

Nakata, Yoshito ... [et al]. Thermal Properties of Ionic Liquid + Water Binary Systems Applied to Heat Pipes. Journal of Chemical \& Engineering Data 2011, 56(5): 1840-1846

\section{ISSUE DATE:}

2011-05-12

URL:

http://hdl.handle.net/2433/259145

\section{RIGHT:}

This document is the Accepted Manuscript version of a Published Work that appeared in final form in Journal of Chemical \& Engineering Data, copyright $\odot$ American Chemical Society after peer review and technical editing by the publisher. To access the final edited and published work see https://doi.org/10.1021/je100839v; この論文は出版社版で ありません。引用の際には出版社版をご確認ご利用ください。; This is not the published version. Please cite only the published version. 


\title{
Thermal Properties of Ionic Liquid + Water Binary
}

\section{Systems Applied to Heat Pipes}

\author{
Yoshito Nakata ${ }^{1)}$, Kimio Kohara ${ }^{2)}$ and Rika Hagiwara ${ }^{1) *}$
}

1) Graduate School of Energy Science, Kyoto University, Yoshida-Honmachi, Sakyo-ku, Kyoto, 6068501 Japan

2) DENSO CORP., 500-1 Minamiyama, Komenoki-cho, Nisshin, Aichi, 470-0111 Japan

*Corresponding author

Rika Hagiwara

E-mail: hagiwara@energy.kyoto-u.ac.jp

Fax: $+81-75-753-5906$

Tel: $+81-75-753-5822$ 
Thermal properties were investigated for binary mixtures of water and five ionic liquids: 1-butyl-3methylimidazolium iodide ([bmim][I]), 1-butyl-3-methylimidazolium tetrafluoroborate ([bmim] $\left.\left[\mathrm{BF}_{4}\right]\right)$, 1-butyl-3-methylimidazolium thiocyanate ([bmim][SCN]), 1-ethyl-3-methylimidazolium ethylsulfate ([emim] $\left[\mathrm{EtSO}_{4}\right]$ ), and 1-ethyl-3-methylimidazolium trifluoromethanesulfonate ([emim][TfO]). The thermal stability was examined by thermogravimetry. The phase behavior was investigated by differential scanning calorimetry from room temperature to $153 \mathrm{~K}$ and phase diagrams were constructed. Vapor pressures were measured using static method in the temperature range of (313 to 343) $\mathrm{K}$ and in the concentration range of mole fraction ( 0 to 0.65$)$ of ionic liquids. It was found that [emim] $[\mathrm{TfO}]+$ $\mathrm{H}_{2} \mathrm{O}$ mixtures are promising for working fluids in heat pipes. Loop heat pipe operation tests were also performed at (313 to 393) K using the mixtures. 


\section{Introduction}

We have proposed application of ionic liquid (IL) + water binary mixtures as working fluids of heat pipes. It is expected that the IL + water working fluids would neither break down the heat pipe container below $273 \mathrm{~K}$ by freezing due to the volume expansion of the mixture nor decompose at as high as $473 \mathrm{~K}$. ILs are made of only organic and/or inorganic ions without solvents. Today, the term is commonly used for salts whose melting point is relatively low (below $373 \mathrm{~K}$ ). In particular, the salts that are liquids at room temperature are called room temperature ionic liquids (RTILs). Recently, considerable efforts have been devoted to the application of RTILs owing to their unique properties. Most of RTILs possess negligible vapor pressures and nonflammability at temperatures of interest, and high thermal decomposition temperatures as well as wide liquid temperature ranges as well as excellent stability in air and water. These features make ionic liquids suitable for application of IL + water binary mixtures to the working fluids for heat pipes. Kim reported IL + water binary mixtures for working fluids of absorption heat pumps. ${ }^{1}$ In spite of the recent rise in the rate of research on ILs, comparatively little is still known on the properties of their mixtures and solutions in other solvents. A detailed knowledge of the behavior of IL + water mixtures is certainly important both from industrial and fundamental perspectives. It is necessary to elucidate the thermal properties of IL + water binary mixtures to select suitable mixtures for working fluids as well as design heat pipes. In this study, five hydrophilic ILs commercially available have been selected, whose reported melting points are below $273 \mathrm{~K}$ and thermal decomposition temperatures are above $473 \mathrm{~K}^{2-3}$ Melting points, thermal decomposition temperatures and vapor pressures of their water mixtures were measured as a function of concentration. An examination of a heat pipe was also conducted using 1-ethyl-3-methylimidazolium trifluoromethanesulfonate that exhibited the best properties for the fluid component.

\section{Experimental Section}

Materials. 1-butyl-3-methylimidazolium iodide ([bmim][I]) (Tokyo Chemical Industry Co., Ltd., purity $>97.0 \mathrm{wt} \%$ ), 1-butyl-3-methylimidazolium tetrafluoroborate ([bmim][BF 4$)$ (Kanto Chemical Co., Inc., purity 95 wt\%), 1-butyl-3-methylimidazolium thiocyanate ([bmim][SCN]) (Fluka, purity $>95$ wt\%), 1-ethyl-3-methylimidazolium ethylsulfate ([emim] $\left.\left[\mathrm{EtSO}_{4}\right]\right)($ Fluka, purity $>95 \mathrm{wt} \%)$, and 1ethyl-3-methylimidazolium trifluoromethanesulfonate ([emim][TfO]) (Tokyo Chemical Industry Co., Ltd., purity $>98.0 \mathrm{wt} \%$ ) were used as received. Each IL was mixed with distilled water at various compositions and vigorously stirred by a vortex mixer for 1 minute. The water content of the ILs before mixing were $(0.3$ to 1.0$) \%$ as measured by the Karl Fischer method, which produces the uncertainty for the composition of the mixture. The uncertainty increases with the increase of IL content in the mixture, however, it is within mole fraction \pm 0.05 in the present study. 
Thermogravimetry. Thermal decomposition temperatures of IL + water binary mixtures were measured by a differential thermogravimetric analyzer Shimadzu DTG-60/60H. A volume of $10 \mu \mathrm{L}$ for each sample was put into aluminum pans. Temperature was elevated from room temperature to $873 \mathrm{~K}$ with a scan rate of $10 \mathrm{~K} \cdot \mathrm{min}^{-1}$. Measurements were performed under a flow of dry nitrogen gas.

Differential scanning calorimetry. Determination of phase transition temperatures of neat ILs and IL + water binary mixtures was performed by means of a differential scanning calorimeter Shimadzu DSC60. DSC curves were obtained for the sample of $5 \mu \mathrm{L}$ in the temperature range (153 to 293 ) $\mathrm{K}$ with the scan rate of $10 \mathrm{~K} \cdot \mathrm{min}^{-1}$. Neat ILs were dried at $373 \mathrm{~K}$ for $1 \mathrm{~h}$ in the DSC before measurements. Measurements were performed under a flow of dry nitrogen gas. Binary mixtures were sealed in aluminum pans with caps to avoid the evaporation of water which changes the concentration of the sample.

Vapor pressure measurements. The total vapor pressures of IL + water binary mixtures were determined by a static method using a pressure transducer KEYENCE AP-10S with a sensitivity of 0.1 $\mathrm{kPa}$. The schematic illustration of the experimental apparatus used in this study is shown in Figure 1. The tube placed in a thermoregulated air bath is connected with compression fittings to a pressure transducer and vacuum system. An internal volume of the apparatus was estimated to be $6 \mathrm{~mL}$. The sample with a volume of $1.0 \mathrm{~mL}$ was placed in the glass test tube of $10 \mathrm{~mm}$ inner diameter. To avoid any concentration variation due to the evaporation of water, sample was degassed as follows. The sample was frozen once with liquid nitrogen and gases over the solid were removed under vacuum $(0.2$ $\mathrm{Pa}$ ). Then the solid sample was melted and the gases dissolved in the sample were removed by evacuation after freezing once again the liquid. This treatment was repeated three times. For the vapor pressure measurement, the temperature was elevated stepwise with $5 \mathrm{~K}$ increments from (313 to 343 ) $\mathrm{K}$. Equilibrium at constant pressure was within (30 to 60) minutes after each shift of temperature. The temperatures were measured using a K-type thermocouple with an accuracy of $\pm 1.0 \mathrm{~K}$. The uncertainty of the vapor pressure arising from the uncertainty of temperature measurement was estimated within $\pm 1.4 \mathrm{kPa}$, the vapor pressure reproducibility for a replicate sample was within $\pm 0.1 \mathrm{kPa}$, the total uncertainty was within $1.5 \mathrm{kPa}$. The uncertainty of the composition in the liquid phase was estimated within mole fraction \pm 0.05 considering the variation caused by the holdup of water over the liquid in the vapor form.

Loop heat pipe operation tests. Loop heat pipe operation tests were carried out using IL + water binary mixtures and pure water, respectively as working fluids. The experimental apparatus is schematically shown in Figure 2. The apparatus is constructed with stainless steel pipes and partially PFA pipes for flow visualization. The evaporator consists of six heaters in a copper block. The temperatures of the evaporator and internal working fluid were measured respectively at three positions shown in the figure. The condenser was cooled by a $1 \mathrm{~L} \cdot \mathrm{min}^{-1}$ flow of tap water at $298 \mathrm{~K}$. The working 
fluid temperature in the condenser and the temperatures of tap water at the inlet and outlet of the condenser were monitored. All the temperatures were measured using a K-type thermocouple with an accuracy of $\pm 1.0 \mathrm{~K}$. The supplied heat ranged from (50 to 450$) \mathrm{W}$. The test was performed with various volumes of working fluids, and the total pressure inside the container was measured by a pressure transducer placed at the bottom of the apparatus.

\section{Results and discussion}

Thermal stability. The TG curves of each IL + water binary mixture are shown in Figure 3. Two steps in the degradation curves are observed for each mixture. The first step is ascribed to the evaporation of water and the second to the decomposition of the IL. The latter decomposition temperature is the same as that of the corresponding neat IL and does not depend on the composition of the mixture.

From these results, the ILs studied are assumed to be stable up to at least $473 \mathrm{~K}$ and some of them are much higher than that. However, tests carried out under static temperatures have shown that the decomposition temperature is about $373 \mathrm{~K}$ lower than that obtained from dynamic TG measurements. ${ }^{4}$ Decomposition rates on the order of $1 \% \cdot \mathrm{h}^{-1}$ at $523 \mathrm{~K}$ have been reported ${ }^{5}$ for [emim] $\left[\mathrm{BF}_{4}\right]$ and [bmim $]\left[\mathrm{BF}_{4}\right]$. Long-term thermal stability of IL should be examined in detail for practical applications.

Phase diagram. The ILs studied here tend to exhibit supercooled states and the freezing temperatures observed are not always reproducible. Once the mixture is frozen, it shows a reproducible melting temperature within $\pm 1 \mathrm{~K}$. Therefore, in this study, discussions are made on the melting temperatures rather than freezing temperatures. A baseline shift corresponding to glass transition was observed for each neat IL in the temperature range of (213 to 183) K. For [emim][TfO], a peak corresponding to melting was also observed at $265 \mathrm{~K}$. The glass transition temperatures are determined as the intersection of the baseline and the tangent of the heat capacity change. The melting temperatures are determined as the intersection of the baseline and the tangent of the endothermic peak. These results agree with the literature values ${ }^{2-3}$ within a few degrees「ここに文献值を入れる」.

Figure 4 shows phase diagrams of IL + water binary systems. The melting temperatures of the mixtures are determined at the top of the peaks since it is difficult to determine the onset of broad melting transition peak. For $[\mathrm{bmim}][\mathrm{I}]+\mathrm{H}_{2} \mathrm{O}$ mixtures, in the cooling process of the DSC measurement, the liquid was supercooled in the present condition and a glass transition was observed at (183 to 163 ) $\mathrm{K}$ in a wide range of composition except for the neat [bmim][I] that showed glass transition at $211 \mathrm{~K}$ in the same condition. For $X_{\mathrm{IL}}<0.4$, a new peak corresponding to the melting of water appeared.

It has been reported previously that as in their pure states, [bmim][I] ion pairs form clusters for $X_{\mathrm{IL}}>$ $0.5 .^{6}$ In addition, it is suggested by analogy with studies of aqueous nonelectrolytes ${ }^{7}$ that $\mathrm{H}_{2} \mathrm{O}$ molecules are adsorbed on the surface of such IL clusters and act as discrete species, weakly interacting together through hydrogen-bonding, as opposed to bulk water. Therefore, no peak corresponding to the melting 
of water is observed in IL-rich region. The glass transition temperature is considered to be lowered due to the viscosity decrease caused by the addition of water. ${ }^{8}$ Except for $[\mathrm{emim}][\mathrm{TfO}]+\mathrm{H}_{2} \mathrm{O}$ mixtures, similar tendencies are observed for the phase diagram of the other binary mixtures. The concentration of IL above which the $\mathrm{H}_{2} \mathrm{O}$ molecules in the mixture cannot form ice is lowered as the hydrophilicity of the IL anion is increased.

The phase diagram of [emim][TfO] $+\mathrm{H}_{2} \mathrm{O}$ binary system is a simple eutectic type. The eutectic point is found at $X_{\mathrm{IL}}=0.5$ with the temperature of $233 \mathrm{~K}$.

Vapor pressure. In order to check the reliability of the experimental setup, vapor pressure data of water as a function of temperature was measured and compared with the literature ${ }^{9}$. The experimental data is in agreement with the calculated data from Antoine's equations with a maximum relative deviation of $0.7 \mathrm{kPa}$.

The vapor pressures of IL + water binary mixtures were measured for various IL amounts ranging from (50 to 95$) \%$ in volume fraction, and the effect of ILs on the vapor pressure of water was investigated. The temperature dependences of vapor pressure with different compositions are shown in Figure 5. Ideal vapor pressures according to the Raoult's law are also indicated in the figure.

The effect of the IL on the non-ideality of a solution can be expressed by activity coefficients of water $\gamma_{\mathrm{w}}$, which was calculated by the following equation ${ }^{10}$ :

$$
\gamma_{\mathrm{w}}=y_{\mathrm{w}} \cdot \varphi_{\mathrm{w}} \cdot P_{\exp } / x_{\mathrm{w}} \cdot \varphi^{\mathrm{s}} \cdot P_{\mathrm{w}}^{\mathrm{s}}
$$

where $P_{\exp }$ and $P_{\mathrm{w}}^{\mathrm{s}}$ are the vapor pressures of the mixture and pure water at system temperature, respectively. $P_{\mathrm{w}}^{\mathrm{s}}$ was calculated from Antoine's equations with Antoine constants taken from the literature ${ }^{9} . y_{\mathrm{w}}$ and $x_{\mathrm{w}}$ are the mole fraction of water in the vapor phase and liquid phase, respectively. $\varphi_{\mathrm{w}}$ is the fugacity coefficient of water in the vapor mixture, and $\varphi^{\mathrm{s}}{ }_{\mathrm{w}}$ is the fugacity coefficient of pure water in its saturated state at a given temperature.

For an IL + water binary system, the vapor phase is pure water due to the nonvolatility of IL, and thus $y_{\mathrm{w}}=1$. Since the pressures at the temperature range in this measurement are sufficiently low, both the fugacity coefficients can be approximated as 1 in the limited accuracy of the present experiment. Therefore, eq. 1 can be simplified as follows:

$$
\gamma_{\mathrm{w}}=P_{\exp } / P_{\mathrm{w}}^{\mathrm{s}} \cdot X_{\mathrm{w}}
$$

According to eq. 2, the experimental activity coefficient of the water in an IL + water binary mixture can be calculated from the vapor pressure data. The activity coefficients of water in the studied systems 
at $333 \mathrm{~K}$ at which the measured data for pure water was most accurate are shown in Figure 6 as a function of IL concentration.

The degrees of non-ideality for the binary systems studied were different from each other. The positive deviation from $\gamma_{\mathrm{w}}=1$ for the ideal mixture often found in the water-rich region is attributed to disruption of water-water hydrogen bonding by added IL. Thus, the activity of water exceeds that in the corresponding ideal mixture. On the other hand, the negative deviation in rather IL-rich region is attributed to stabilization of most $\mathrm{H}_{2} \mathrm{O}$ molecules by IL clusters on which the $\mathrm{H}_{2} \mathrm{O}$ molecules are strongly adsorbed by electrostatic interaction. The boundary compositions of these positive and negative deviations in the systems seem to be correlated with the composition above which the melting of free water was not observed in the DSC measurements.

A large positive deviation of the vapor pressure of $[\mathrm{bmim}][\mathrm{I}]+\mathrm{H}_{2} \mathrm{O}$ mixture from that derived from Raoult's equations for an ideal solution suggests weak interaction between [bmim][I] and $\mathrm{H}_{2} \mathrm{O}$ in addition to the destruction of hydrogen-bonded water structure. On the other hand, the lowering of the vapor pressure in $[\mathrm{emim}][\mathrm{TfO}]+\mathrm{H}_{2} \mathrm{O}$ system relative to the pure water is nearly in accordance with the Raoult's law. These results suggest that the interaction between [emim][TfO] and water coincides with the sum of that by themselves.

Heat pipe performance. Thermal decomposition temperature of [emim $][\mathrm{TfO}]+\mathrm{H}_{2} \mathrm{O}$ mixtures was the highest among the systems examined in this study. In addition, it has been pointed out that the heat pipes charged with the [emim][TfO] $+\mathrm{H}_{2} \mathrm{O}$ mixtures may not crack at temperatures to $233 \mathrm{~K}$ because of the presence of liquid phase. ${ }^{11}$ Therefore, loop heat pipe operation tests were performed using [emim][TfO] $+\mathrm{H}_{2} \mathrm{O}$ mixtures as the best IL + water working fluids selected in this study. Figure 7 shows the temperature difference between the evaporator $\left(T_{\mathrm{oh}}\right)$ and input water to the condenser $\left(T_{\mathrm{w} 1}\right)$ with different heat inputs. A small temperature difference corresponds to an effective heat transfer from the evaporator to the condenser by the heat pipe. The heat pipe using [emim] $[\mathrm{TfO}]+\mathrm{H}_{2} \mathrm{O}$ mixtures worked properly with a volume of $11.0 \mathrm{~mL}$ in this system. Moreover, with a volume of $13.3 \mathrm{~mL}$, it showed performance as good as in the case of pure water. Thus, the heat pipe experiments were quite successful. With a volume of $10.0 \mathrm{~mL}$, however, the temperature of the evaporator rose swiftly due to the dry-out of the heating area with both [emim][TfO] $+\mathrm{H}_{2} \mathrm{O}$ mixtures and pure water. Thus, the adequate volume has been optimized for an effective operation of the heat pipe using the IL + water working fluid.

\section{Conclusion}

We have presented thermal decomposition temperatures, phase diagrams, and vapor pressures for five $\mathrm{IL}+$ water binary systems. It was found that the decomposition temperature is independent of the water content in the mixture. In the phase diagrams of the IL + water binary systems except for [emim][TfO] 
$+\mathrm{H}_{2} \mathrm{O}$, the peak corresponding to the melting of water appeared only in $\mathrm{H}_{2} \mathrm{O}$-rich region. In the IL-rich region, $\mathrm{H}_{2} \mathrm{O}$ molecules are considered to be adsorbed on the surfaces of IL clusters and act as a discrete species. On the other hand, the phase diagram of [emim] $[\mathrm{TfO}]+\mathrm{H}_{2} \mathrm{O}$ binary system was a simple eutectic type. The degree of non-ideality was studied for the binary systems in terms of activity coefficients of water calculated from vapor pressure data, and their liquid structure was modeled to be consistent with their phase behavior. These studies led to the conclusion that [emim] [TfO] $+\mathrm{H}_{2} \mathrm{O}$ mixtures are most suitable among the tested systems for working fluids of heat pipes from the viewpoint of liquid temperature range. Loop heat pipe operation tests were successfully performed using [emim] $[\mathrm{TfO}]+\mathrm{H}_{2} \mathrm{O}$ mixtures. 


\section{Literature Cited}

(1) Kim, K.-S.; Park, S.-Y.; Choi, S.; Lee, H. Vapor Pressures of the 1-Butyl-3-methylimidazolium Bromide + Water, 1-Butyl-3-methylimidazolium Tetrafluoroborate + Water, and 1-(2-Hydroxyethyl)-3methylimidazolium Tetrafluoroborate + Water Systems. J. Chem. Eng. Data 2004, 49, 1550-1553.

(2) Zhang, S.; Sun, N.; He, X.; Lu, X.; Zhang, X. Physical Properties of Ionic Liquids: Database and Evaluation. J. Phys. Chem. Ref. Data 2006, 35, 1475-1517.

(3) Fernandez, A.; Torrecilla, J. S.; Garca, J.; Rodriguez, F. Thermophysical Properties of 1-Ethyl-3methylimidazolium Ethylsulfate and 1-Butyl-3-methylimidazolium Methylsulfate Ionic Liquids. $J$. Chem. Eng. Data 2007, 52, 1979-83.

(4) Kosmulski, M.; Gustafsson, J.; Rosenholm, J. B. Thermal stability of low temperature ionic liquids revisited. Thermochim. Acta 2004, 412, 47-53.

(5) Van Valkenburg, M.E.; Vaughn, R. L.; Williams, M; Wilkes, J. S. IONIC LIQUID HEAT TRANSFER FLUIDS. 15th Symposium of Thermophysical Properties; Boulder, CO., 2003.

(6) Katayanagi, H.; Nishikawa, K.; Shimozaki, H.; Miki, K.; Westh, P.; Koga, Y. Mixing Schemes in Ionic Liquid- $\mathrm{H}_{2} \mathrm{O}$ Systems: A Thermodynamic Study. J. Phys. Chem. B 2004, 108, 19451-19457.

(7) Koga, Y. Mixing Schemes in Aqueous Solutions of Nonelectrolytes: A Thermodynamic Approach. J. Phys. Chem. 1996, 100, 5172-5181.

(8) Rodriguez, H.; Brennecke, J. F. Temperature and Composition Dependence of the Density and Viscosity of Binary Mixtures of Water + Ionic Liquid. J. Chem. Eng. Data 2006, 51, 2145-2155.

(9) Zhao, J.; Dong, C.-C.; Li, C.-X.; Meng, Z.-H.; Wang, Z.-H. Isobaric vapor-liquid equilibria for ethanol-water system containing different ionic liquids at atmospheric pressure. Fluid Phase Equilib. 2006, 242, 147-153.

(10) Gmehling, J.; Onken, U. Vapor-Liquid Equilibrium Data Collection; DECHEMA: Frankfurt, 1977.

(11) Imura, H.; Koito, Y.; Mochizuki, M.; Fujimura, H. Start-up from the frozen state of two-phase thermosyphons. Appl. Therm. Eng. 2005, 25, 2730-2739. 


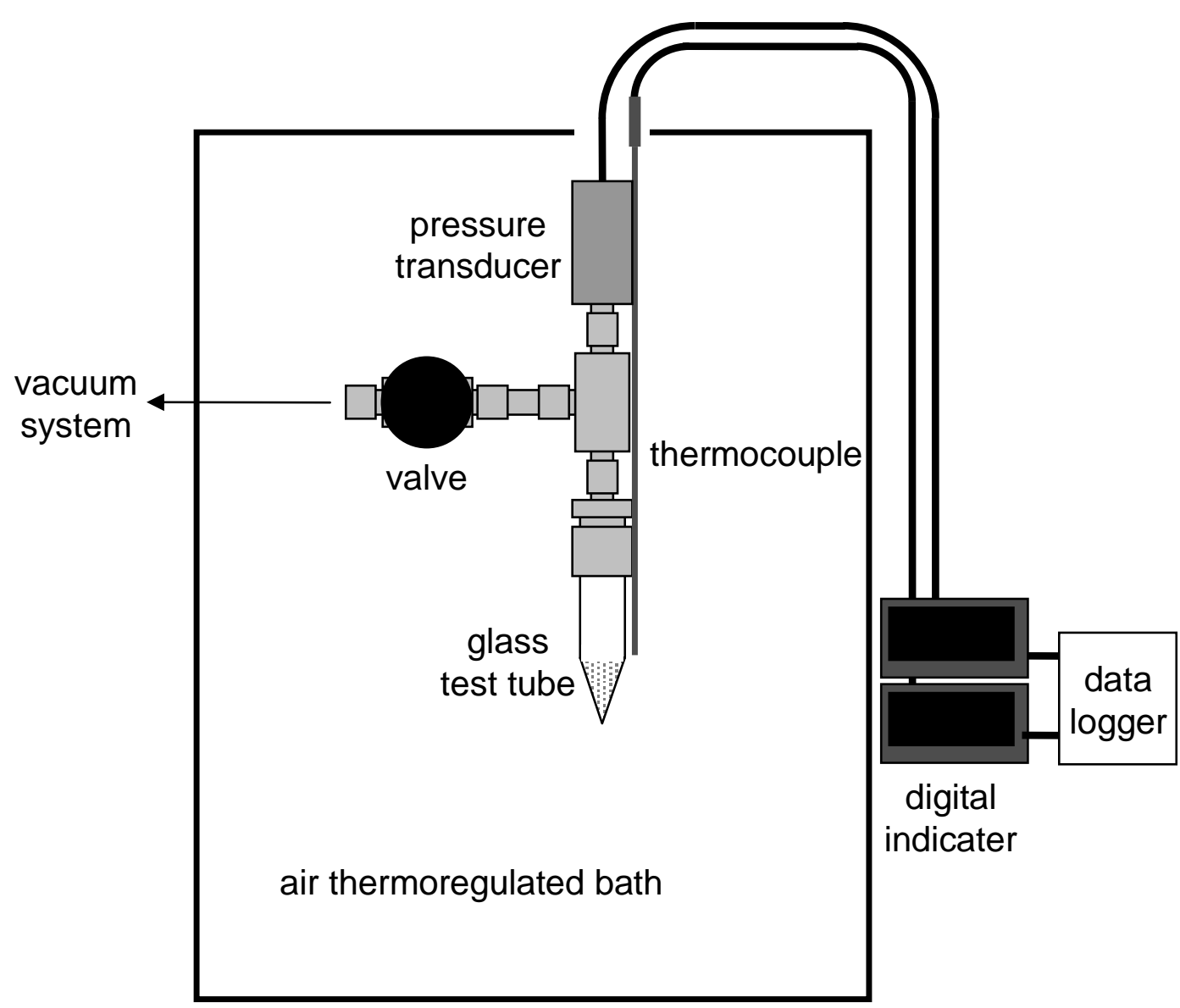

Figure 1. Schematic illustration of the experimental apparatus for vapor pressure measurements. 


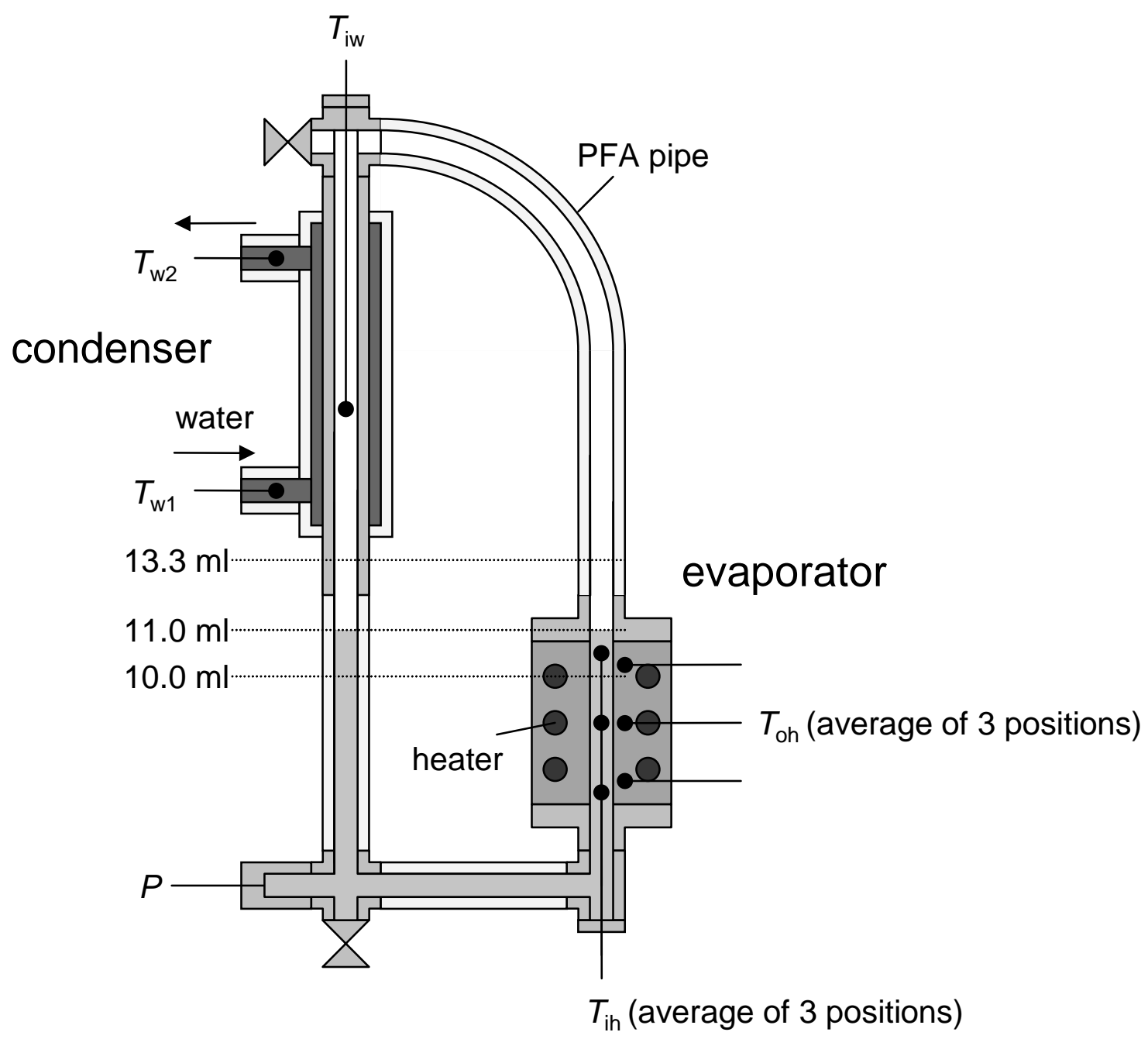

Figure 2. Schematic illustration of the experimental apparatus for loop heat pipe operation tests. 

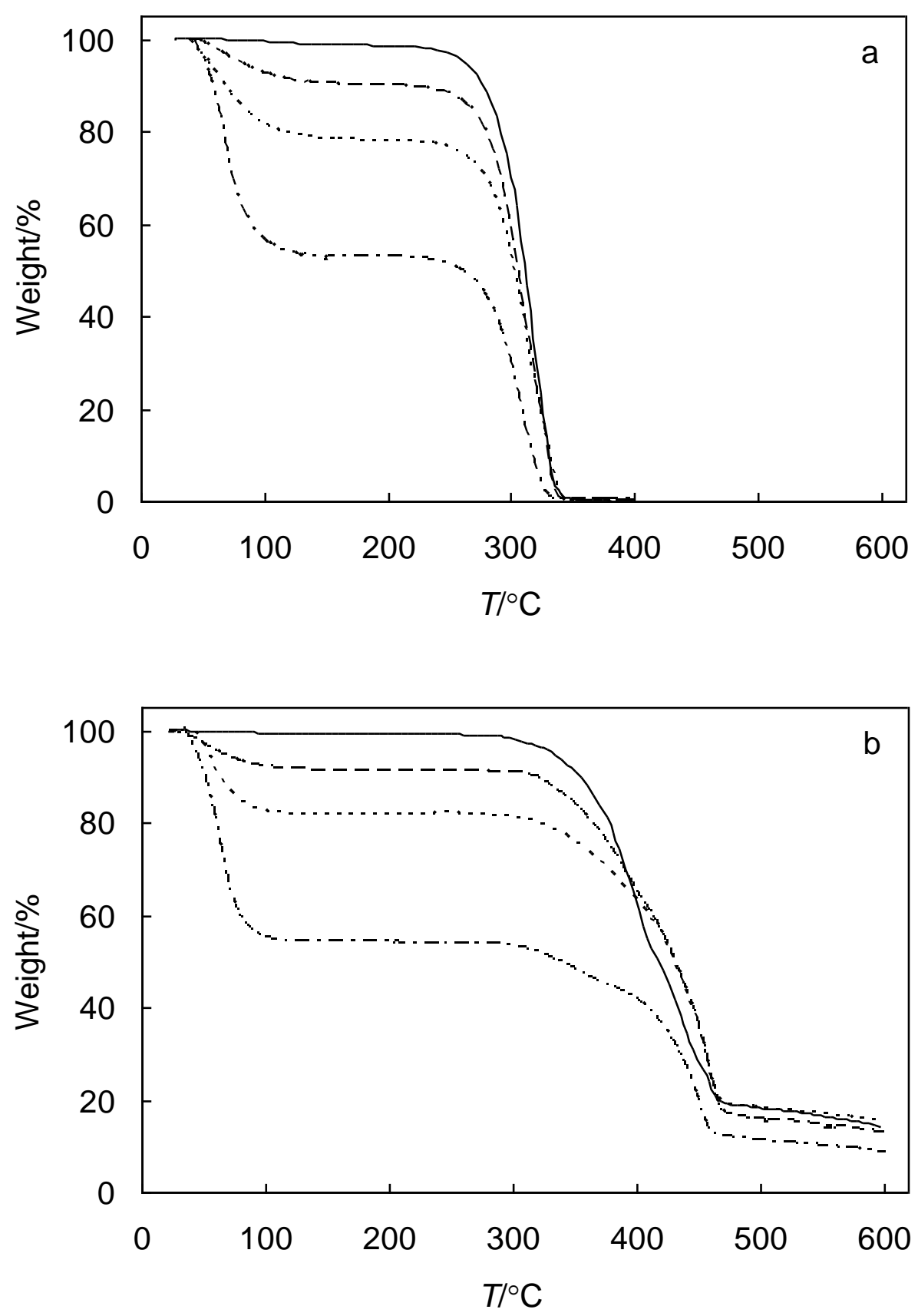

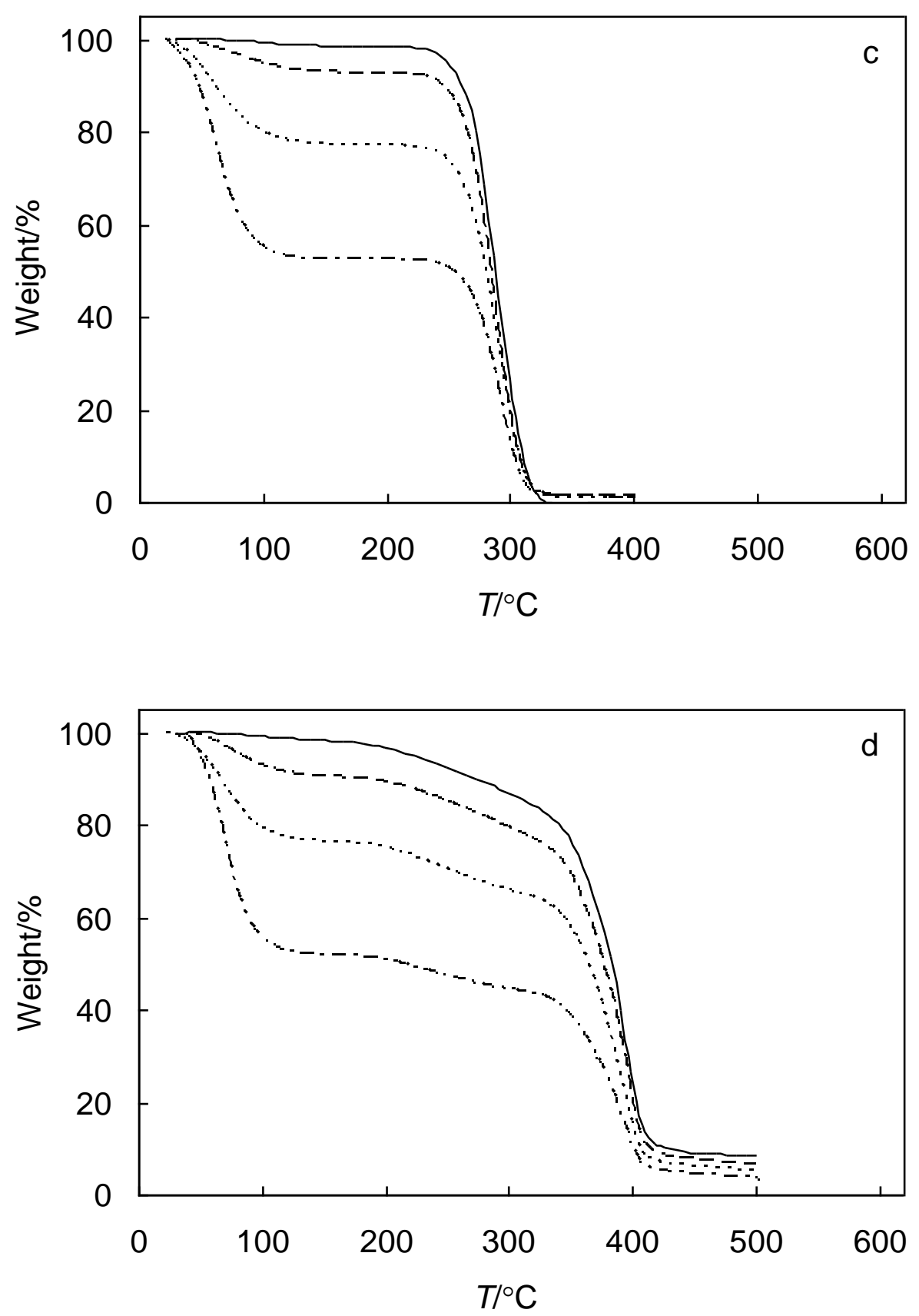


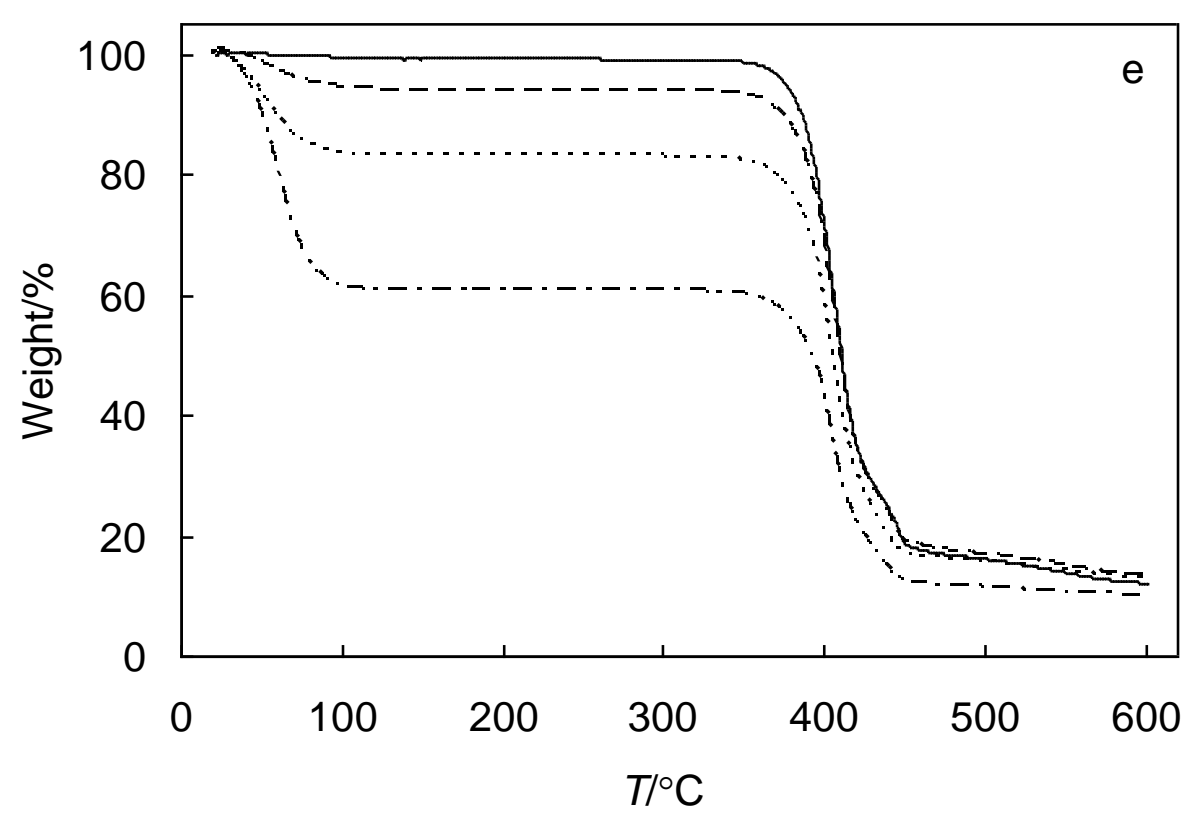

Figure 3. TG curves of IL + water binary mixtures at different volume percent of IL at the heating rate of $10{ }^{\circ} \mathrm{C} \cdot \mathrm{min}^{-1}$ : ---, 50 vol \%; ---, 75 vol \%; --, 90 vol \%; -, 100 vol \%. IL: (a) [bmim][I] (b) $[\mathrm{bmim}]\left[\mathrm{BF}_{4}\right](\mathrm{c})[\mathrm{bmim}][\mathrm{SCN}](\mathrm{d})[\mathrm{emim}]\left[\mathrm{EtSO}_{4}\right](\mathrm{e})[\mathrm{emim}][\mathrm{TfO}]$. 

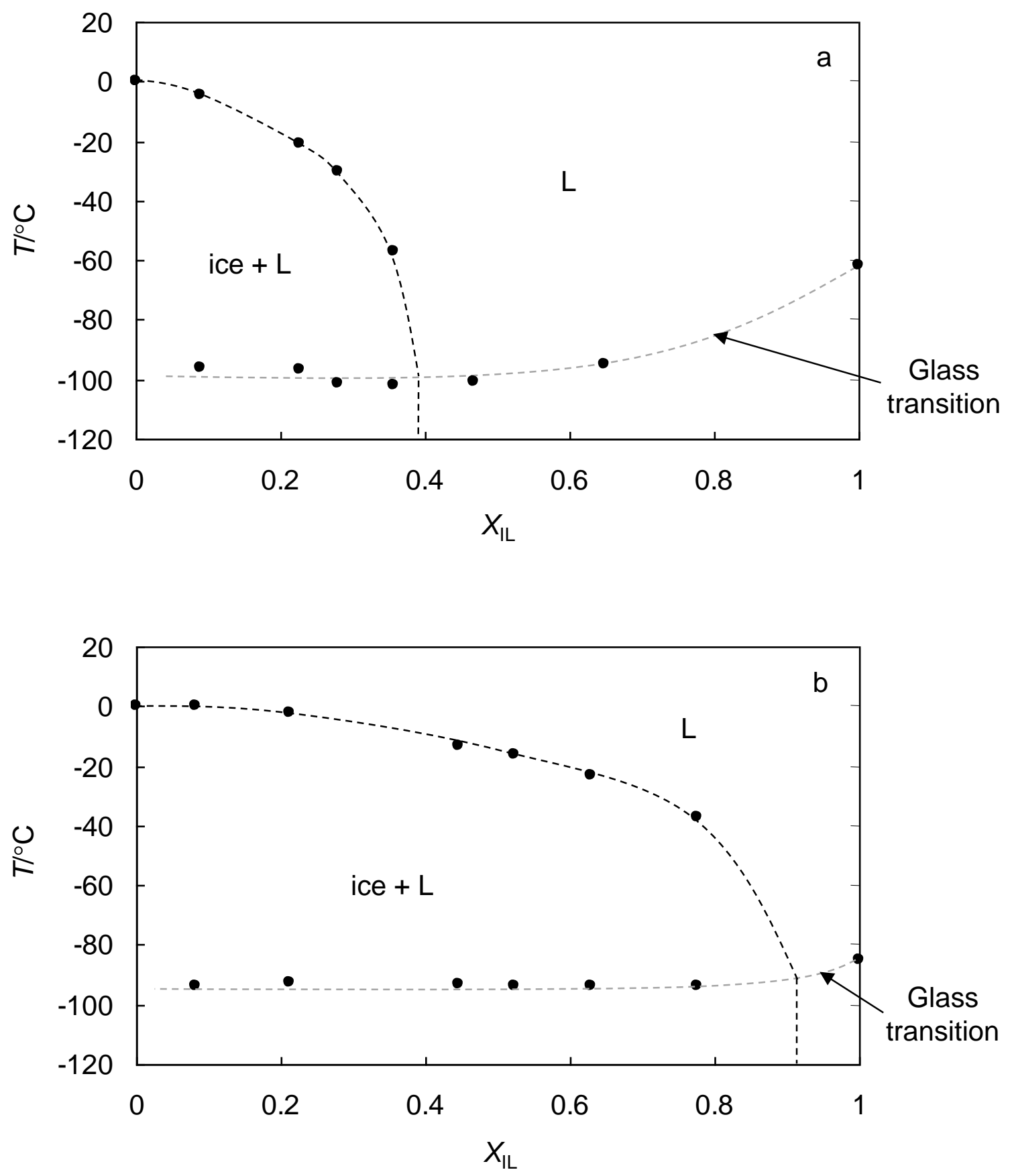

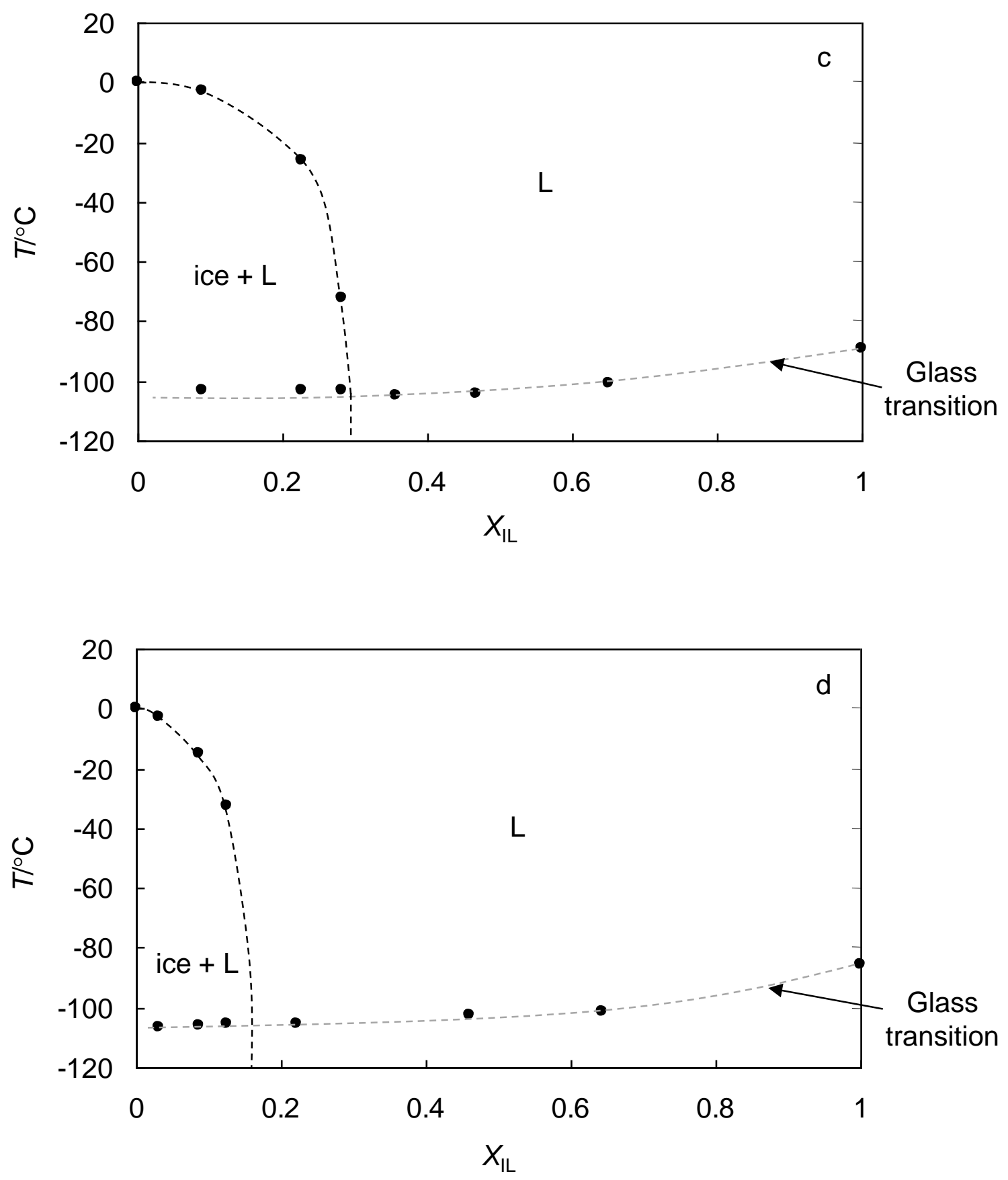


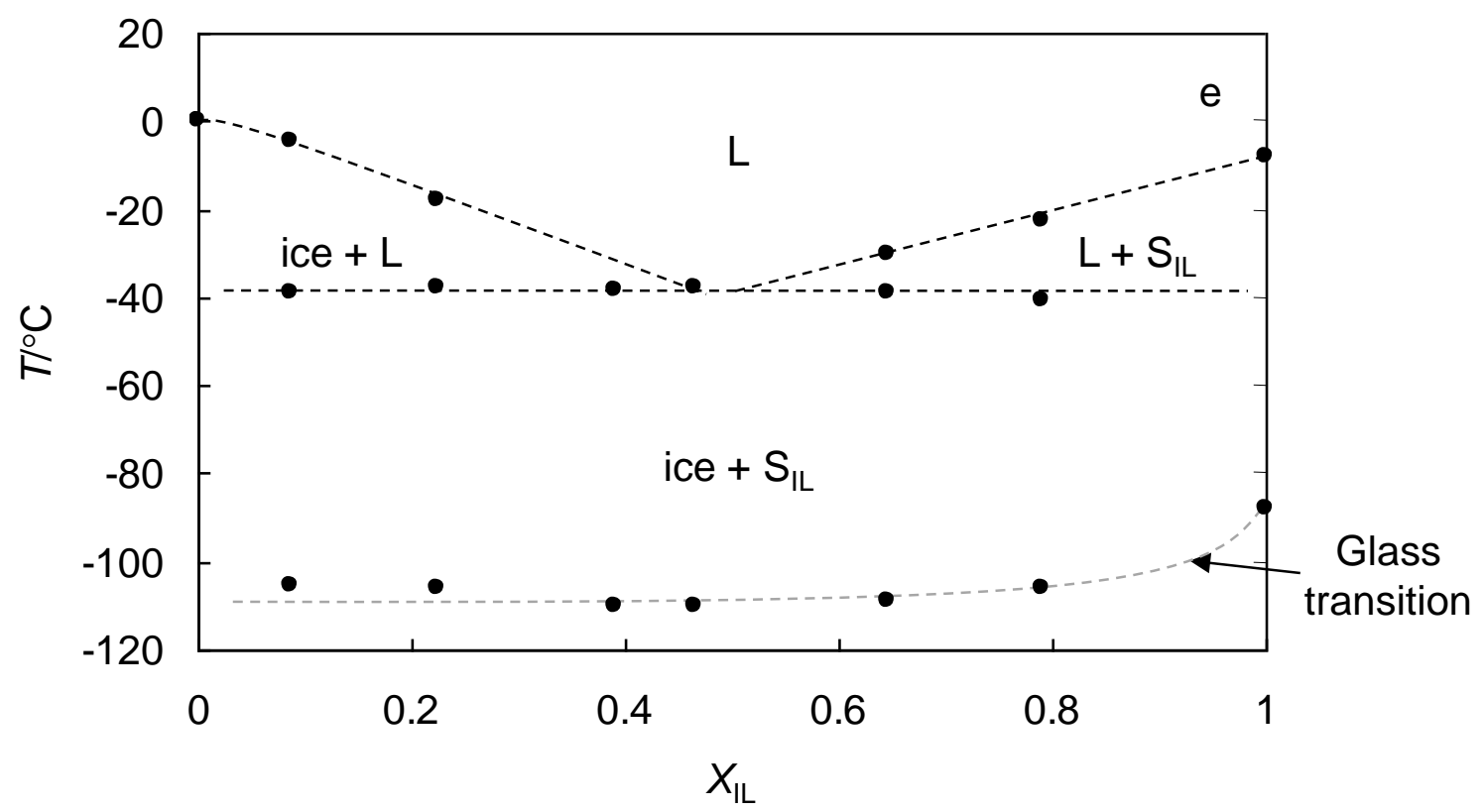

Figure 4. Phase diagrams of IL + water binary systems. IL: (a) $[\mathrm{bmim}][\mathrm{I}]$ (b) $[\mathrm{bmim}]\left[\mathrm{BF}_{4}\right]$ (c) $[\mathrm{bmim}][\mathrm{SCN}](\mathrm{d})[\mathrm{emim}]\left[\mathrm{EtSO}_{4}\right](\mathrm{e})[\mathrm{emim}][\mathrm{TfO}]$. 

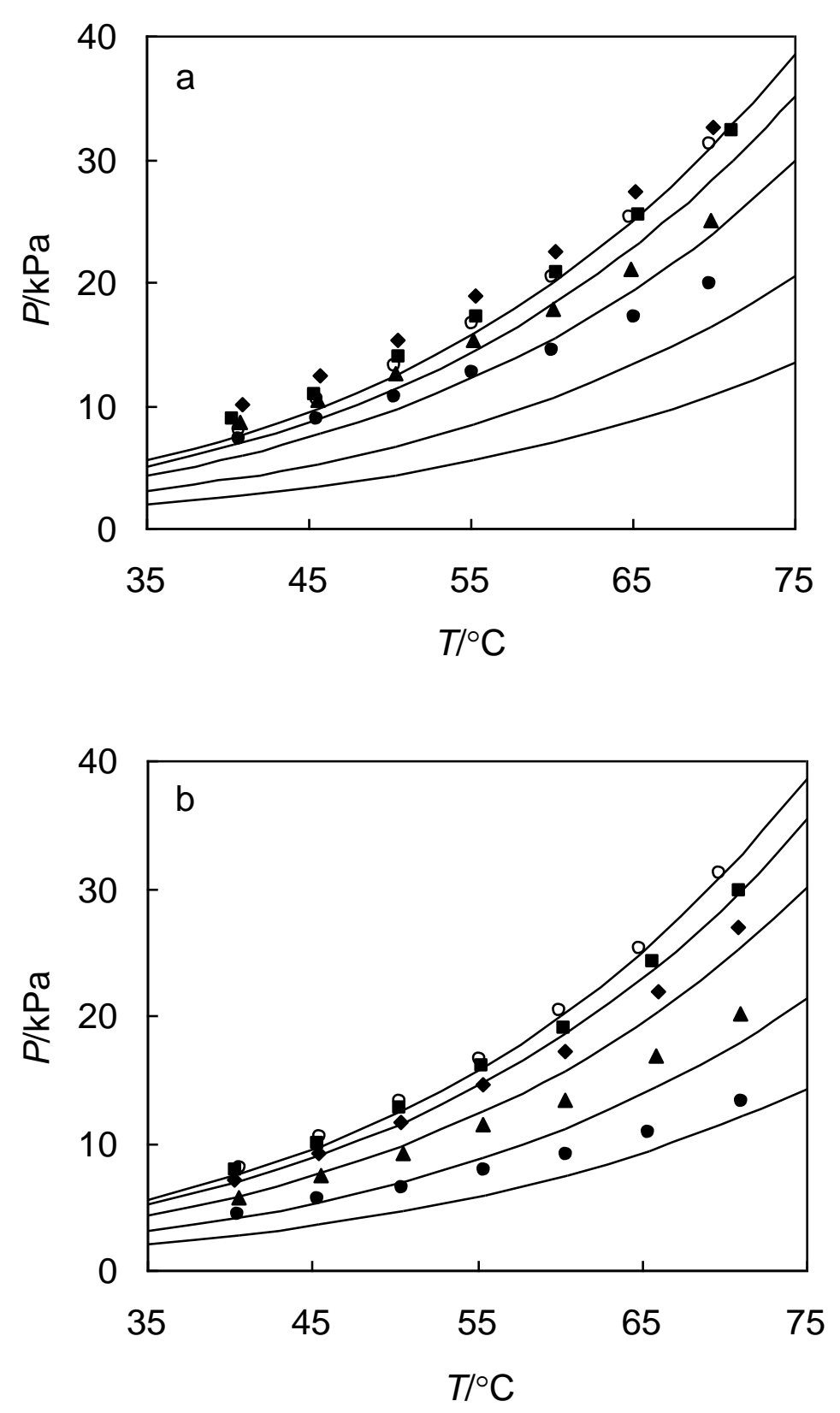

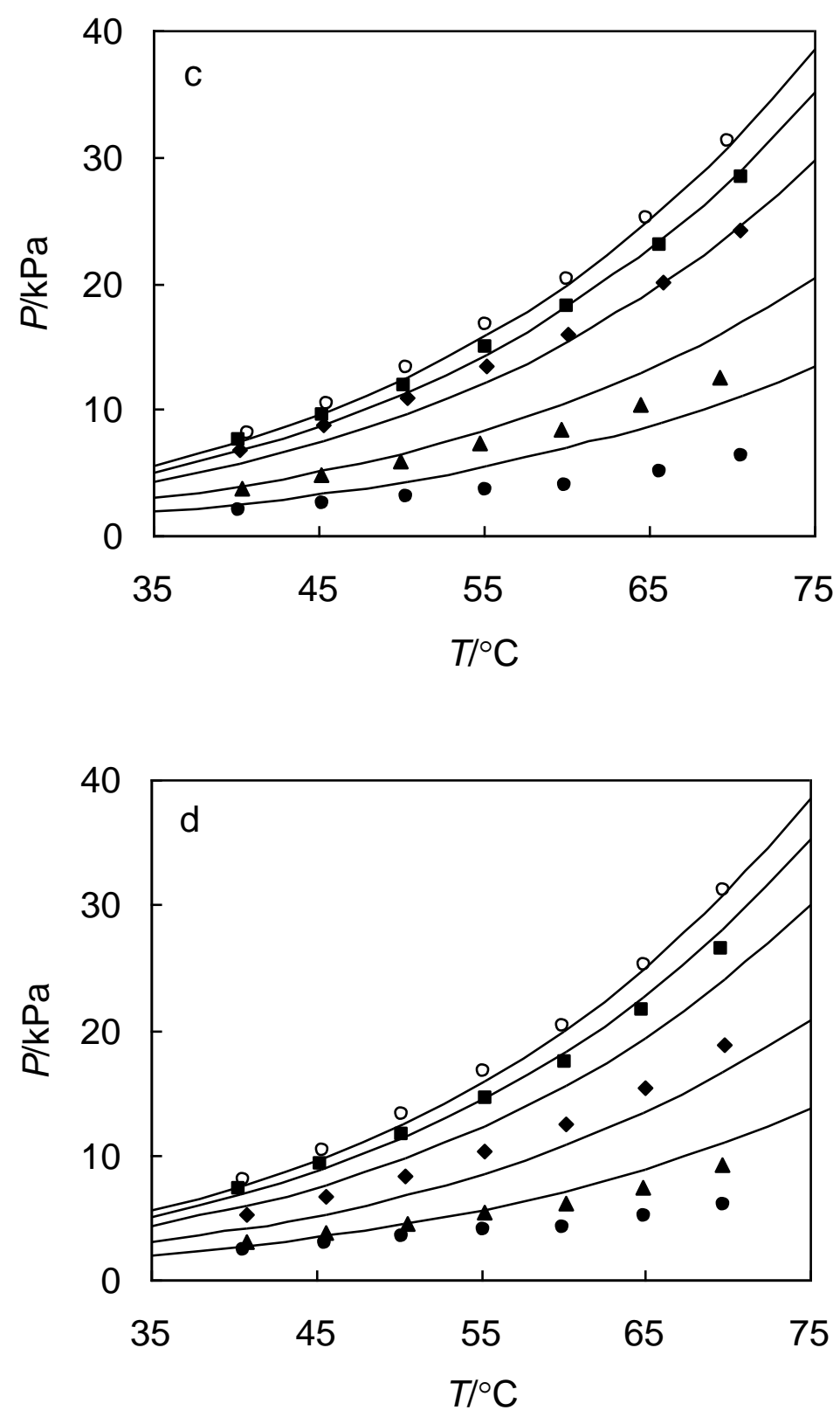


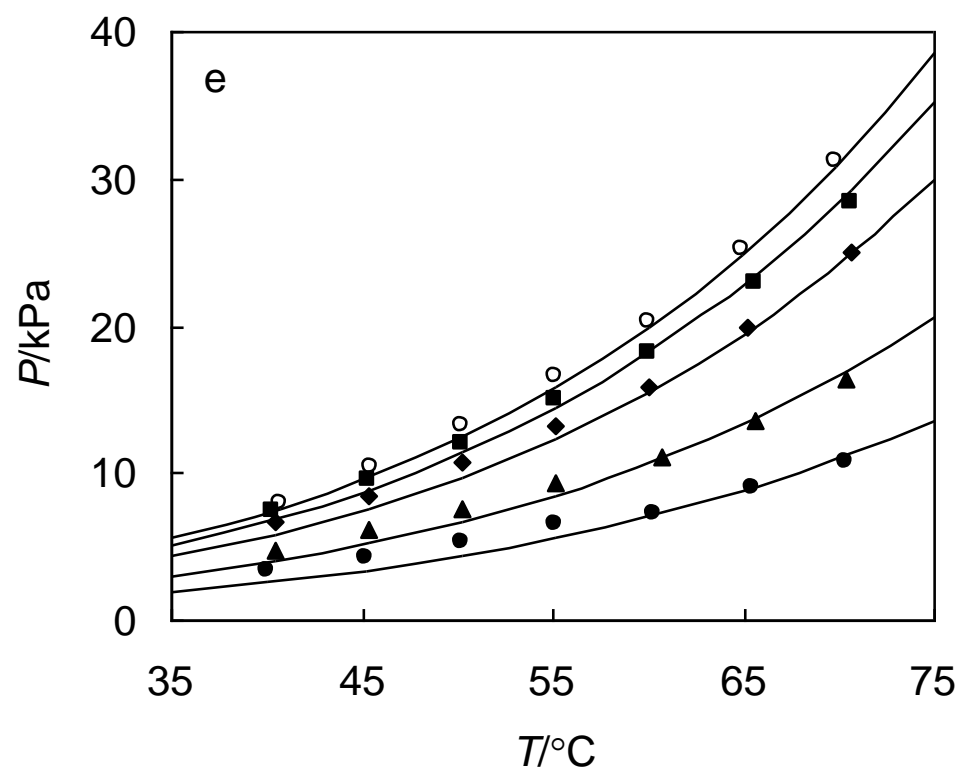

Figure 5. Vapor pressures of IL + water binary mixtures as a function of temperature at different volume percent of IL: $\bigcirc, 0$ vol \% (pure water); $\boldsymbol{\square}, 50$ vol \%; $\diamond, 75$ vol \%; $\boldsymbol{\Delta}, 90$ vol \%;, 95 vol \%. The solid lines represent the ideal behavior of the mixture according to the Raoult's law. IL: (a) $[\mathrm{bmim}][\mathrm{I}](\mathrm{b})[\mathrm{bmim}]\left[\mathrm{BF}_{4}\right]$ (c) $[\mathrm{bmim}][\mathrm{SCN}](\mathrm{d})[\mathrm{emim}]\left[\mathrm{EtSO}_{4}\right](\mathrm{e})[\mathrm{emim}][\mathrm{TfO}]$. 

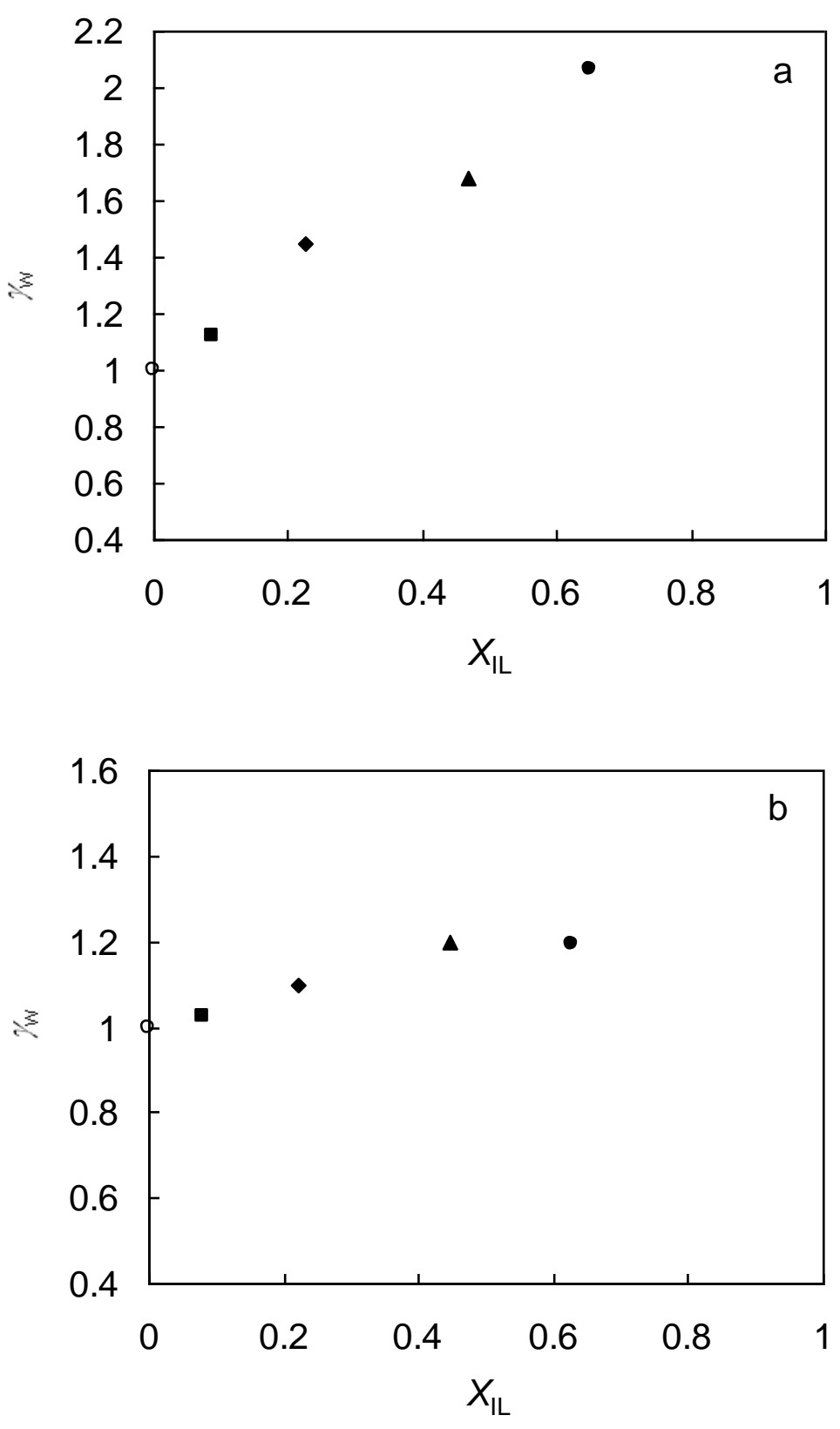

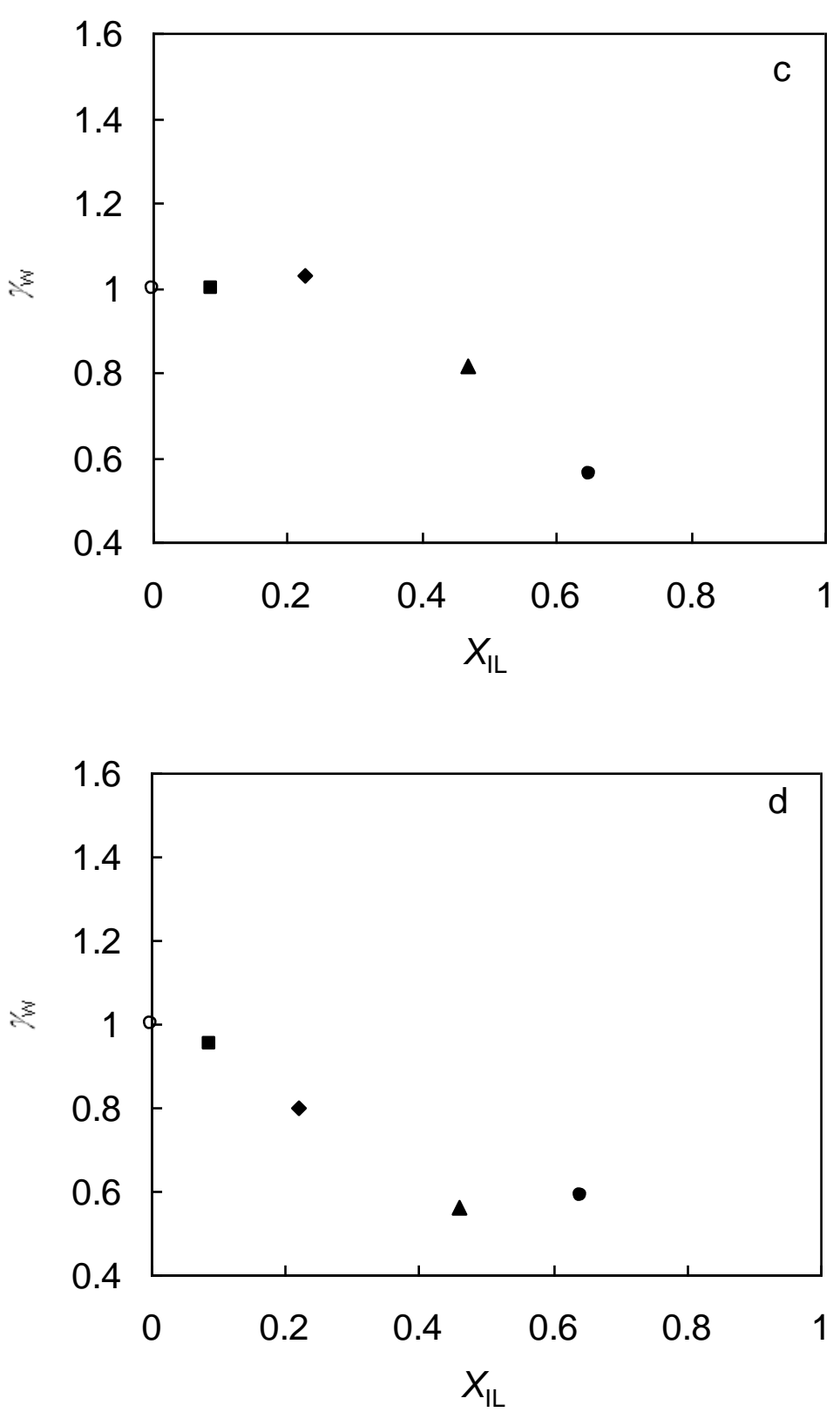


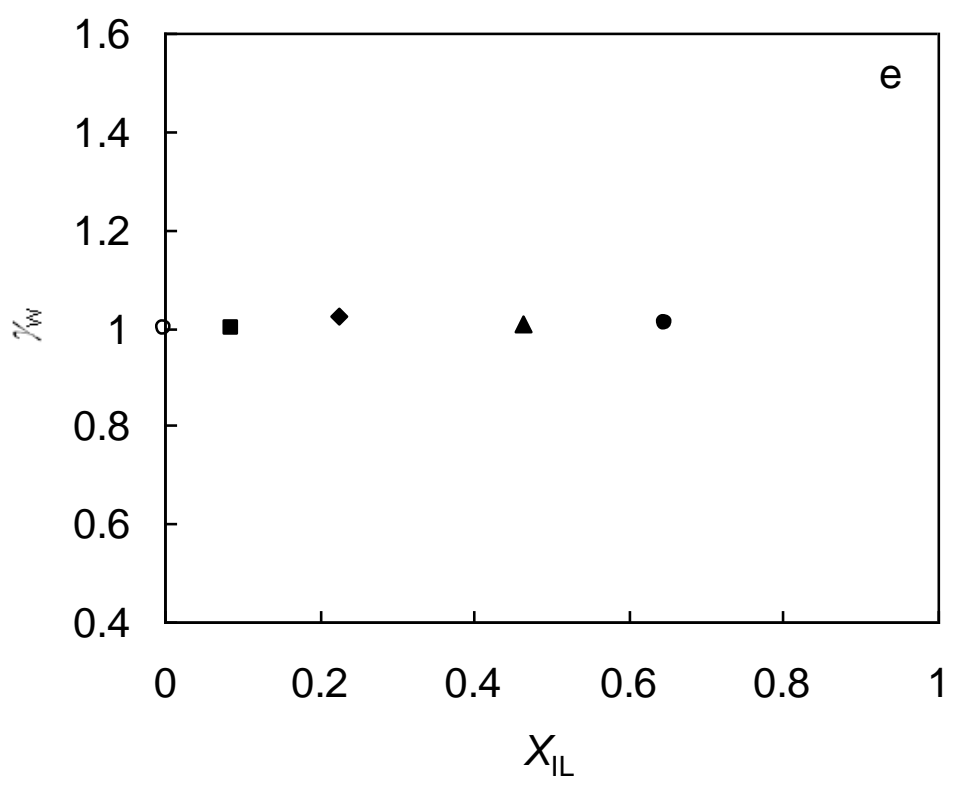

Figure 6. Activity coefficients of water in IL + water binary mixtures at $333 \mathrm{~K}$ as a function of molar ratio of IL: $\bigcirc, 0$ vol \% (pure water); $\boldsymbol{\square}, 50$ vol \%; $>$, 75 vol \%; $\boldsymbol{\Delta}, 90$ vol \%;, 95 vol \%. IL: (a) $[\mathrm{bmim}][\mathrm{I}](\mathrm{b})[\mathrm{bmim}]\left[\mathrm{BF}_{4}\right](\mathrm{c})[\mathrm{bmim}][\mathrm{SCN}](\mathrm{d})[\mathrm{emim}]\left[\mathrm{EtSO}_{4}\right](\mathrm{e})[\mathrm{emim}][\mathrm{TfO}]$. 


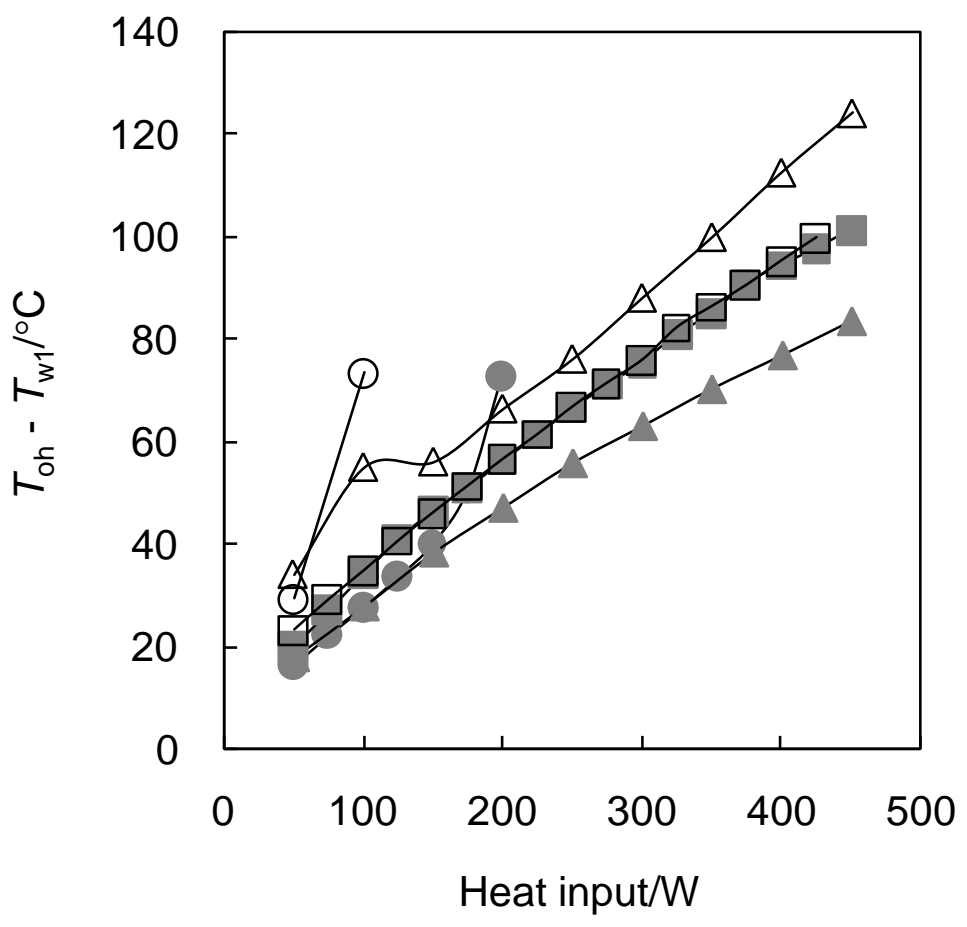

Figure 7. Heat pipe performance using pure water and [emim] $[\mathrm{TfO}]+\mathrm{H}_{2} \mathrm{O}$ mixtures: $\bigcirc$, IL solution (33.0 vol \%) $10.0 \mathrm{~mL}$; $\triangle$, IL solution (30.0 vol \%) $11.0 \mathrm{~mL} ; \square$, IL solution $(24.8 \mathrm{vol} \%$ ) $13.3 \mathrm{~mL}$; $\bigcirc$, pure water $10.0 \mathrm{~mL}$; $\triangle$, pure water $11.0 \mathrm{~mL}$; $\square$, pure water $13.3 \mathrm{~mL}$. 